SHORT REPORT

\title{
Verapamil induced gingival enlargement in cluster headache
}

\author{
M S Matharu, J A van Vliet, M D Ferrari, P J Goadsby
}

J Neurol Neurosurg Psychiatry 2005;76:124-127. doi: 10.1136/jnnp.2003.024240

Verapamil is an effective prophylactic treatment for cluster headaches and, therefore, is widely used. This report describes four patients with cluster headache who developed gingival enlargement after initiating treatment with verapamil. In two patients, it was possible to control this side effect adequately by optimising oral hygiene and dental plaque control. In the other two patients, lowering of the verapamil dose, in addition to optimal oral hygiene and dental plaque control, was necessary; in one patient verapamil had to be stopped completely to reverse the gingival enlargement. Doctors treating cluster headache with verapamil need to be aware of this side effect, especially as it may be preventable with good dental hygiene and dental plaque control, is reversible with reduction or cessation of verapamil, and can lead to dental loss.

C luster headache is an excruciating form of primary headache. ${ }^{12}$ Its management includes treatment with abortive and preventive agents. ${ }^{3}$ Sumatriptan (subcutaneous $6 \mathrm{mg}^{4}$ and intranasal $20 \mathrm{mg}^{5}$ ) and high dose, high flow rate oxygen ${ }^{6}$ are effective abortive agents in most patients. Several drugs, including verapamil, ${ }^{8}$ methysergide, ${ }^{9}$ lithium, ${ }^{8}$ and corticosteroids, ${ }^{10}$ are reported to be effective in the preventive treatment of cluster headache.

Verapamil is an effective preventive agent in both episodic and chronic cluster headache. In an open trial employing verapamil at doses of $240-600 \mathrm{mg}$ daily in episodic cluster headache and 120-1200 mg daily in chronic cluster headache, an improvement of more than $75 \%$ was noted in 33 of $48(69 \%)$ patients. $^{7}$ A recent double blind, placebo controlled, parallel group trial evaluated the efficacy of verapamil $360 \mathrm{mg}$ daily over a two week period in 26 patients with cluster headache. The study showed a statistically significant reduction in the frequency of the headaches and the consumption of analgesics in the patients treated with verapamil. ${ }^{11}$ Verapamil dosages commonly employed range from $240 \mathrm{mg}$ to $960 \mathrm{mg}$ daily in divided doses. ${ }^{3}$ In chronic cluster headaches, patients who respond to verapamil are often continued on it indefinitely, and it is generally well tolerated. Constipation is the commonest side effect, although hypotension, conduction defects, bradycardia, ankle oedema, nausea, and fatigue may also occur. ${ }^{12} 13$

We report four patients with cluster headache who were treated with verapamil and, consequently, developed gingival enlargement. We describe the management of this adverse effect in our patients and discuss what general measures can be taken to minimise gingival enlargement in patients in whom long term verapamil therapy is being considered.

\section{CASE REPORTS}

Case 1

A 32 year old woman developed intermittent daily headaches in 1997 for which she was referred the following year. She was diagnosed as having chronic cluster headache. Her medications included subcutaneous sumatriptan $6 \mathrm{mg}$ prn (when required), which abbreviated the attack, and sodium valproate. In the past she had tried methysergide, sumatriptan tablets $100 \mathrm{mg}$ prn and ergotamine tablets $2 \mathrm{mg}$ prn, all of which were completely ineffective. Sodium valproate was discontinued and the patient started on verapamil, the dose of which was gradually increased to $760 \mathrm{mg}$ daily under regular electrocardiogram (ECG) monitoring. There was a marked improvement with verapamil, resulting in a significant reduction in the frequency, duration, and severity of the cluster attacks. The only side effects she initially reported were mild constipation, lethargy, and ankle oedema.

About three months after starting verapamil she noticed that her interdental papillae had enlarged. A further three months later she saw a dentist who diagnosed gingival enlargement secondary to verapamil. However, as verapamil had dramatically improved the cluster headaches, the patient was reluctant to discontinue it. Dental plaque was removed by scaling and the patient was advised to maintain good oral hygiene. Over the next 18 months, despite regular professional dental care, the gingival enlargement continued to worsen gradually, with development of generalised nodular swelling and encroachment of the crowns of the adjacent teeth. In addition, the patient reported intermittent bleeding from the gums, especially after meals. In May 2000, she was persuaded to try other cluster headache preventive agents, while continuing verapamil. She had trials of lithium $400 \mathrm{mg}$ twice daily and topiramate $200 \mathrm{mg}$ twice daily, with which there was no improvement. During this period, the gingival enlargement continued to worsen and, in addition, the patient began to complain of discomfort from her teeth, especially when eating and looseness of the upper incisors. In January 2001, a course of intravenous dihydroergotamine $9 \mathrm{mg}$ over three days was administered with dramatic improvement. The patient now had only two to four cluster attacks per week with each attack lasting only about 1530 minutes. Verapamil and lithium were stopped without any deterioration in the cluster headaches. Over the next three months, the gingival enlargement, gum bleeding, and dental discomfort and looseness of teeth resolved completely.

\section{Case 2}

A 40 year old man developed cluster headaches in 1992 for which he was referred in June 2001. He was diagnosed as having chronic cluster headache. His medications included subcutaneous sumatriptan $6 \mathrm{mg}$ prn, high dose and flow rate oxygen, verapamil $240 \mathrm{mg}$ daily, sodium valproate $600 \mathrm{mg}$ daily, lithium $300 \mathrm{mg}$ daily, ergotamine tablets $2 \mathrm{mg}$ daily, 
methysergide $1 \mathrm{mg}$ daily, and prednisolone $10 \mathrm{mg}$ daily Subcutaneous sumatriptan and oxygen were effective, abbreviating the attacks to 15-30 minutes. The combination of verapamil, sodium valproate, lithium, ergotamine, methysergide, and prednisolone was ineffective in suppressing the cluster attacks. The patient had started verapamil in December 2000. In the past he had tried indometacin $150 \mathrm{mg}$ daily and amitriptyline.

Sodium valproate, lithium, and prednisolone were discontinued. The verapamil dose was gradually increased to $600 \mathrm{mg}$ daily under regular ECG monitoring over two months; there was mild improvement in the cluster headaches. He was then seen elsewhere and lithium $600 \mathrm{mg}$ daily, methysergide $2 \mathrm{mg}$ daily, and prednisolone $15 \mathrm{mg}$ daily were added. In addition, the patient was administered intravenous dihydroergotamine (IV DHE) $17.5 \mathrm{mg}$ over seven days; he was rendered pain free while receiving the IV DHE but the attacks recurred within a day of stopping the infusion. There was no added benefit with this combination of drugs.

He consulted again in September 2001, when he was advised to stop lithium, methysergide, and prednisolone. The verapamil dose was increased to $720 \mathrm{mg}$ daily, which completely suppressed the cluster attacks. Unfortunately, two months later the patient noticed gingival enlargement with intermittent bleeding. We advised him to reduce the verapamil dose to $480 \mathrm{mg}$ daily and to see a periodontist. The periodontist diagnosed gingival enlargement secondary to verapamil; the patient was advised to maintain good dental hygiene and given a course of antibiotics for possible infection, although there was no evidence for this. On reducing the verapamil dose, the cluster attacks recurred but, over the next two months, the gingival enlargement resolved completely. Interestingly, in May 2002, he took $1 \mathrm{~g}$ of "magic mushrooms" (containing psilocybin) which rendered him pain free for one month; since then he has been taking magic mushrooms $1 \mathrm{~g}$ once every one to two months, which renders him pain free for two to six weeks. He continues to take verapamil $480 \mathrm{mg}$ daily and has no gingival problems.

\section{Case 3}

A 37 year old man developed intermittent daily headaches in 1996 for which he was referred to our clinic and was diagnosed as having chronic cluster headache. In the past he had taken sumatriptan tablets $100 \mathrm{mg}$ prn, pizotifen, atenolol, amitriptyline, carbamazepine, indometacin $50 \mathrm{mg}$ three times daily, paroxetine, and diazepam, none of which produced any benefit. The patient was started on verapamil, the dose of which was increased to $400 \mathrm{mg}$ daily under ECG monitoring over one month. Verapamil $400 \mathrm{mg}$ daily completely suppressed the cluster headaches. He reported no side effects. Reduction of the verapamil dose led to recurrence of the headaches.

One year after starting verapamil, the patient noted the onset of gingival enlargement. Two months later, he developed bleeding from the gums, especially after meals and when brushing his teeth; in addition, the gingival enlargement continued to worsen gradually. A further two months later, he began to complain of discomfort from his teeth when eating. He then saw a dentist who diagnosed gingival enlargement secondary to verapamil. Dental plaque was removed and the patient was advised to maintain good oral hygiene by thoroughly brushing his teeth twice a day and rinsing his mouth with plain water after each meal. The possibility of substituting verapamil with another cluster headache preventive agent was raised but the patient declined the offer. Over the next six months all the dental symptoms gradually resolved.

\section{Case 4}

An 18 year old man developed intermittent daily headaches at the age of 12 years for which he was referred in 1999. His medications included subcutaneous sumatriptan $6 \mathrm{mg}$ prn, indometacin $25 \mathrm{mg}$ four times daily, and amitriptyline $75 \mathrm{mg}$ once daily. Subcutaneous sumatriptan aborted the headache within five minutes. Indometacin and amitriptyline were ineffective. In the past, he had tried prednisolone $60 \mathrm{mg}$ daily, verapamil $240 \mathrm{mg}$ daily, diltiazem $180 \mathrm{mg}$ daily, and propranolol $160 \mathrm{mg}$ daily. The headaches were completely suppressed by prednisolone $60 \mathrm{mg}$ daily but recurred when the dose was reduced. Verapamil $240 \mathrm{mg}$, diltiazem, and propranolol were completely ineffective. A diagnosis of chronic cluster headache was made. Indometacin and amitriptyline were stopped. The patient was started on verapamil, the dose of which was gradually increased to $480 \mathrm{mg}$ daily under regular ECG monitoring. Verapamil $480 \mathrm{mg}$ daily completely suppressed the cluster attacks. In February 2000, a few days after the patient received meningococcal group $\mathrm{C}$ vaccination, the cluster headaches recurred at a frequency of one to two attacks daily. The verapamil dose was increased to $640 \mathrm{mg}$ daily under ECG monitoring, which completely suppressed the cluster attacks again.

In April 2000, he had a syncopal episode during which he lost consciousness for a few minutes. The cardiologists advised the patient to reduce the verapamil dose to $480 \mathrm{mg}$ daily while he was being investigated for a cardiac abnormality. The cluster headaches recurred on reducing the verapamil dose. Lithium carbonate $600 \mathrm{mg}$ daily was started and the dose gradually titrated to $1200 \mathrm{mg}$ daily, under serum lithium level monitoring. This combination of verapamil and lithium completely suppressed the cluster attacks. Subsequently, 24 hour ECG monitoring, exercise stress test, and an echocardiogram were reported to be normal. The option of monotherapy with verapamil was raised but the patient chose to continue taking verapamil and lithium as the combination was very effective.

In September 2001, the patient reported mild discomfort from his teeth and intermittent bleeding from the gums, especially when eating. He had noticed that he had moderate gingival enlargement, although he remarked that the gingival enlargement had probably been present for several months, but he had paid little notice to it. He had prominent interdental papillae and moderate generalised nodular swelling. He saw a dentist in November 2001 who diagnosed gingival enlargement. Dental plaque was removed and the patient was advised to maintain good oral hygiene. The dental symptoms gradually regressed over the ensuing six months.

\section{DISCUSSION}

Gingival enlargement or overgrowth is a side effect associated with the administration of several drugs. These drugs can be basically divided into three groups: anticonvulsants, the immunosuppressant ciclosporin, and calcium channel blockers. Recent therapeutic trends in the treatment of, particularly chronic, cluster headache ${ }^{14}$ have led to more widespread use of very high doses of the medicine, up to $960 \mathrm{mg}$ daily, to be used more commonly. ${ }^{15}$ Our cases illustrate that verapamil can produce gum enlargement and given the exceptional doses of the medicine used in neurological practice it seems important to be aware of this problem and of its management.

Of the calcium channel blockers, the commonest agent associated with the development of gingival enlargement is nifedipine, ${ }^{16}{ }^{17}$ though similar problems have been associated with the administration of verapamil, ${ }^{18-20}$ felodipine, ${ }^{21}$ nitrendipine, $^{22}$ diltiazem, ${ }^{23}$ and amlodipine. ${ }^{23}$ The incidence of 
verapamil induced gingival hyperplasia is poorly defined. The only study that has addressed this issue identified one patient with gingival enlargement out of 24 dentate patients who used verapamil for more than one year, giving an incidence of $4.2 \% .^{19}$ This is lower than the $14-83 \%$ reported incidence of nifedipine induced gingival enlargement. ${ }^{16}{ }^{24}{ }^{25}$ Currently, the aetiology of drug induced gingival enlargement is not entirely understood, but it is clearly multifactorial. Some of the known risk factors include: presence of gingival inflammation (gingivitis due to poor oral hygiene); presence of dental plaque; and the dose and duration of drug therapy. ${ }^{26-28}$ Gingival enlargement may cause significant morbidity because it poses an oral hygiene and dental plaque control problem; the tooth discomfort may affect mastication; it may alter tooth eruption; it may interfere with speech; and it may cause aesthetic concerns. ${ }^{29}$

The term "gingival hyperplasia" is inappropriate because enlargement does not result from an increase in the number of cells but rather an increase in extracellular tissue volume with an inflammatory infiltrate of predominantly B lymphocytes. ${ }^{30}$ Histologically, in verapamil induced gingival enlargement there is highly vascular connective tissue, acanthotic and thickened epithelium with long rete pegs containing dyskeratotic pearls, and varying amounts of subepithelial inflammatory infiltrate. ${ }^{20}$ The histological picture is strikingly similar to that caused by phenytoin, ciclosporin, and other calcium channel antagonists. The mechanism by which drug induced gingival enlargement occurs is not well understood and may be distinct for each drug. Cell culture studies on gingival fibroblasts from a patient with verapamil induced gingival overgrowth and from control cells obtained from healthy gingiva suggest that verapamil affects the proliferation of selected fibroblasts subpopulations and alters the balance between regeneration and degradation. ${ }^{20}$

In the treatment of drug induced gingival enlargement, the first consideration should be given to the removal of local factors. The clinician should emphasise the importance of dental plaque control. Although the exact role played by dental plaque in drug induced gingival enlargement is unclear, there is evidence that good oral hygiene and frequent professional removal of plaque decreases the degree of gingival enlargement present and improves overall gingival health. ${ }^{31}$ The possibility of discontinuing the offending drugs or of changing the medication should be raised. ${ }^{32}$ Discontinuation of the drug usually results in complete regression of the gingival overgrowth. The options of discontinuing or substituting the medication should be examined in conjunction with the patient. Simple discontinuation of the offending agent is usually not a practical option but replacing it with another medication might be. If the non-surgical approach is not effective, periodontal surgery in the form of gingivectomy or periodontal flap procedures can effectively reduce the enlarged gingival tissues. ${ }^{29}$

We have described four cases of patients with cluster headache who were treated with verapamil and subsequently developed gingival enlargement. The gingival enlargement was first noted at between three months and two years of starting verapamil. In cases 3 and 4 , it was possible to reverse the gingival enlargement with optimum oral hygiene and dental plaque control, without altering the verapamil dose. In case 2, good oral hygiene and dental plaque control together with alterations in the verapamil dose were required to adequately control the gingival symptoms. In case 1, the symptoms were progressive despite good oral hygiene and dental plaque control; verapamil had to be stopped to reverse the symptoms.

These case reports highlight the importance of appreciating that verapamil can cause gingival overgrowth. Patients being considered for treatment with verapamil should be made aware of this potential side effect and encouraged to maintain meticulous oral hygiene. They should be advised to regularly consult an oral medicine specialist for control of dental plaque and monitoring for oral complications associated with gingival enlargement such as the gingivitis, bleeding gums, and loosening of teeth. In patients who develop gingival enlargement, it should be borne in mind that the gingival symptoms may be controlled successfully, even under the continuous administration of verapamil, by meticulous individual and professional oral hygiene. If this is not effective, then the verapamil dose can be reduced or the drug stopped completely. The surgical options should only be considered as a last resort in patients responsive to verapamil and unresponsive to other cluster headache preventive treatments in whom newer surgical approaches cannot be easily or appropriately considered. ${ }^{33}$

\section{Authors' affiliations}

M S Matharu, P J Goadsby, Headache Group, Institute of Neurology, Queen Square, London, UK

J A van Vliet, M D Ferrari, Department of Neurology, Leiden University Medical Centre, the Netherlands

Competing interests: none declared

PJG is a Wellcome Trust Senior Research Fellow.

Correspondence to: Professor P J Goadsby, Institute of Neurology, Queen Square, London WCIN 3BG, UK; peterg@ion.ucl.ac.uk

Received 23 July 2003

In revised form 26 November 2003

Accepted 21 December 2003

\section{REFERENCES}

1 Headache Classification Committee of The International Headache Society. Classification and diagnostic criteria for headache disorders, cranial neuralgias and facial pain. Cephalalgia 1988;8(suppl 7):1-96.

2 Headache Classification Committee of The International Headache Society. The International Classification of Headache Disorders, 2nd edn. Cephalalgia 2004;24(suppl 1):1-160.

3 Dodick DW, Rozen TD, Goadsby PJ, et al. Cluster headache. Cephalalgia 2000;20:787-803.

4 Ekbom K, The Sumatriptan Cluster Headache Study Group. Treatment of acute cluster headache with sumatriptan. N Engl J Med 1991;325:322-6.

5 van Vliet JA, Bahra A, Martin V, et al. Intranasal sumatriptan is effective in the treatment of acute cluster headache-a double-blind placebo-controlled crossover study. Cephalalgia $2001 ; 21: 270-1$.

6 Fogan L. Treatment of cluster headache: a double blind comparison of oxygen vs air inhalation. Arch Neurol 1985;42:362-3.

7 Gabai IJ, Spierings ELH. Prophylactic treatment of cluster headache with verapamil. Headache 1989;29:167-8.

8 Bussone G, Leone M, Peccarisi C, et al. Double blind comparison of lithium and verapamil in cluster headache prophylaxis. Headache 1990;30:41 1-17.

9 Curran DA, Hinterberger H, Lance JW. Methysergide. Res Clin Stud Headache 1967;1:74-122.

10 Jammes JL. The treatment of cluster headaches with prednisone. Dis Nerv Syst 1975;36:375-6.

11 Leone M, D'Amico D, Attanasio A. Verapamil is an effective prophylactic for cluster headache: results of a double-blind multicentre study versus placebo. In: Olesen J, Goadsby PJ, eds. Cluster Headache \& Related Conditions. Oxford: Oxford University Press, 1999:296-9.

12 Thulin T. Calcium antagonists - assessments of side effects. Scan J Prim Health Care 1990;1:81-4.

13 Dougall HT, McLay J. A comparative review of the adverse effects of calcium antagonists. Drug Saf 1996;15:91-106.

14 Olesen J, Goadsby PJ. Cluster headache and related conditions. In: Olesen J, ed. Frontiers in Headache Research. Oxford: Oxford University Press, 1999;9.

15 Matharu MS, Boes CJ, Goadsby PJ. Management of trigeminal autonomic cephalalgias and hemicrania continua. Drugs 2003;63:1637-77.

16 Barclay S, Thomason JM, Idle JR, et al. The incidence and severity of nifedipine-induced gingival overgrowth. J Clin Periodontol 1992;19:311-14.

17 Bullon P, Machuca G, Martinez-Sahuquillo A, et al. Evaluation of gingival and periodontal conditions following causal periodontal treatment in patients treated with nifedipine and diltiazem. J Clin Periodontol 1996;23:649-57.

18 Mehta AV, Chidambaram B, O'Riordan AC. Verapamil-induced gingival hyperplasia in children. Am Heart J 1992;124:535-6.

19 Miller CS, Damm DD. Incidence of verapamil-induced gingival hyperplasia in a dental population. J Periodontol 1992;63:453-6. 
20 Pernu HE, Oikarinen K, Hietanen J, et al. Verapamil-induced gingival overgrowth: a clinical, histologic, and biochemical approach. J Oral Pathol Med 1989; 18:422-5

21 Lombardi T, Fiore-Donno G, Belser U, et al. Felodipine-induced gingival hyperplasia: a clinical and histologic study. J Oral Pathol Med 1991;20:89-92.

22 Brown RS, Sein P, Corio R, et al. Nitrendipine-induced gingival hyperplasia. First case report. Oral Surg Oral Med Oral Pathol 1990;70:593-6.

23 Bullon P, Machuca G, Martinez Sahuquillo A, et al. Clinical assessment of gingival size among patients treated with diltiazem. Oral Surg Oral Med Oral Pathol Oral Radiol Endod 1995;79:300-4

24 Barak S, Engelberg IS, Hiss J. Gingival hyperplasia caused by nifedipine. Histopathologic findings. J Periodontol 1987;58:639-42.

25 Slavin J, Taylor J. Cyclosporin, nifedipine, and gingival hyperplasia. Lancet 1987;2:739.

26 Nuki K, Cooper SH. The role of inflammation in the pathogenesis of gingival enlargement during the administration of diphenylhydantoin sodium in cats. J Periodontal Res 1972;7:102-10.
$27 \mathrm{O}^{\prime}$ Neil TC, Figures KH. The effects of chlorhexidine and mechanical methods of plaque control on the recurrence of gingival hyperplasia in young patients taking phenytoin. BDJ 1982;152:102-10.

28 Fu E, Nieh S, Chang HL, Wang SL. Dose-dependent gingival overgrowth induced by cyclosporin in rats. J Periodontol 1995:66:594-8.

29 Camargo PM, Melnick PR, Pirih FQ, et al. Treatment of drug-induced gingival enlargement: aesthetic and functional considerations. Periodontology 2000;27:131-8.

30 Bullon P, Machuca G, Armas JR, et al. The gingival inflammatory infiltrate in cardiac patients treated with calcium antagonists. J Clin Periodontol 2001;28:897-903.

31 Dongari A, McDonnell HT, Langlais RP. Drug-induced gingival overgrowth. Oral Surg Oral Med Oral Pathol 1993;76:543-8.

32 Harel-Raviv M, Eckler M, Lalani K, et al. Nifedipine-induced gingival hyperplasia. A comprehensive review and analysis. Oral Surg Oral Med Oral Pathol Oral Radiol Endod 1995;79:715-22.

33 Leone M, Franzini A, Bussone G. Stereotatic stimulation of the posterior hypothalamic gray matter in a patient with intractable cluster headache. N Engl J Med 2001;345:1428-9.

\section{$\mathrm{ECHO}$}

\section{Dronabinol reduces central pain in MS}

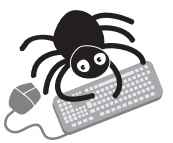

Please visit the Journal of Neurology, Neurosurgery, and Psychiatry website [www.jnnp. com] for a link to the full text of this article.
Datients with central neuropathic pain associated with multiple sclerosis (MS) should have better prospects of pain relief now that a randomised controlled trial in Denmark has shown that an oral synthetic derivative of cannabis is effective. This is a hopeful sign for those whose pain does not respond to current drugs.

The randomised double blind, placebo controlled crossover trial in 24 patients with MS and central pain established that dronabinol up to $10 \mathrm{mg}$ daily for three weeks reduced pain intensity significantly by the end of treatment compared with placebo. The estimated relative difference in pain reduction from baseline between dronabinol and placebo was $-20.5 \%$ ( $95 \%$ confidence interval -37.5 to -4.5 ). Median pain relief score was significantly raised for dronabinol $(3(0-6.7))$ versus placebo $(0(0-2.3))$ too, and mental health was better but functional ability was unchanged. Side effects were widespread, affecting the CNS and including musculoskeletal problems, though these were mostly tolerable once dosage was lowered. The patients were aged 23-55 and had had MS and pain for a median of seven and 4.5 years, respectively.

Cannabis derivatives seem to reduce allodynia or hyperalgesia in neuropathic pain and central pain in animals, and they might be helpful for pain suffered by up to $80 \%$ of MS patients. However, until now it was not known whether they would be effective specifically against central pain reported in about a third of MS patients.

ه Svendsen KB, et al. BMJ 2004;329:253-257. 